\title{
SÍNTESE DE CATALISADORES ZIEGLER-NATTA: ALGUMAS ROTAS E SUAS DIFICULDADES
}

Thaís H. S. Costa, Marcos A. S. Costa, Luiz Claudio de Santa Maria, Fernanda M. B. Coutinho*

Instituto de Macromoléculas Professora Eloisa Mano - Universidade Federal do Rio de Janeiro - CP 68525 - 21945-970 - Rio de Janeiro - RJ

Neusa M. T. Pires

Petroflex - Coperbo - Duque de Caxias - RJ

Recebido em 18/10/95; aceito em 16/8/96

\begin{abstract}
SYNTHESIS OF ZIEGLER-NATTA CATALYSTS: SOME ROUTES AND THEIR DIFFICULTIES. The Ziegler-Natta catalyst and the polymerization thereof are systems which require careful handling and special treatment of chemicals. In spite of the use of inert atmosphere and dry chemicals, some Ziegler-Natta systems may present low activities or even may deactivate because of unsuitable handling. Some features of the $\mathrm{TiCl}_{3}$ synthesis and its characterization when related to the presence of impurities are described. Evidences of poor handling of chemicals and/or laboratory devices while in synthesis of the catalyst are emphasized. The problems arising from butadiene polymerization and some relevant details in propylene polymerization are also presented with teaching objectives.
\end{abstract}

Keywords: Ziegler-Natta catalysts; propylene; butadiene; polymerization.

\section{1 - INTRODUÇÃO}

A preparação de catalisadores Ziegler-Natta geralmente requer várias etapas que incluem tratamentos especiais de reagentes químicos além de manipulação cuidadosa durante o processo de síntese. Assim, o tratamento e seleção de solventes, reagentes e vidraria, e o modo apropriado de manipular esses materiais não podem ser omitidos. Inúmeras patentes ${ }^{1-5}$ descrevem a síntese de catalisadores Ziegler-Natta, mas a simples reprodução de patentes, é um trabalho que exige o conhecimento do processo de síntese incluindo cuidados fundamentais que são omitidos nesse tipo de literatura.

A principal característica de catalisadores baseados em $\mathrm{TiCl}_{3}$ é a sua modificação através da adição de um composto doador de elétrons (base de Lewis) introduzido na etapa de síntese do catalisador. Esta modificação resulta em um catalisador mais ativo e estereoespecífico do que aqueles sintetizados na ausência de base $\mathrm{b}^{6-12}$.

Sabe-se que as partículas de polímero podem replicar as partículas originais do catalisador inclusive a sua estrutura interna $^{13}$. Um bom catalisador para polimerização de $\alpha$-olefinas deve apresentar, entre outras características, bom controle morfológico do polímero resultante. Entende-se aqui por morfologia: forma, textura, granulometria, porosidade e densidade aparente das partículas. Assim, partículas de formato esférico, de diâmetro médio em torno de $500 \mu \mathrm{m}$, baixo conteúdo de finos, estreita distribuição de tamanhos de partícula e alta densidade aparente $\left(\cong 0,5 \mathrm{~g} / \mathrm{cm}^{3}\right)$ são parâmetros morfológicos desejáveis nas poliolefinas produzidas. Os polímeros que apresentam tais características morfológicas eliminam ou reduzem bastante muitos problemas de ordem operacional (produção industrial) ${ }^{14}$.

Embora o $\mathrm{TiCl}_{3}$ seja um catalisador com atividade mais baixa que os catalisadores utilizados por indústrias de poliolefinas com tecnologia mais avançada (catalisadores suportados em $\mathrm{MgCl}_{2}$ e com controle de morfologia ${ }^{15}$ ) e do que os catalisadores metalocênicos que produzem polímeros com características únicas ${ }^{16}$, ele apresenta ainda as seguintes vantagens:

1 - Vários tipos de $\mathrm{TiCl}_{3}$ são descritos em patentes em domínio público o que permite a sua reprodução sem pagamento de royalties;
2 - Viabilidade de síntese em laboratórios com menores recursos técnicos que os necessários à síntese de catalisadores suportados em $\mathrm{MgCl}_{2}$;

3 - Aplicabilidade em vários setores da pesquisa científica, tal como recobrimento de fibras de madeira com polímero através da polimerização do monômero na presença das fibras e $\mathrm{TiCl}_{3}$ para posterior preparação de compósitos polipropileno/fibras de madeira, polietileno de alta densidade/fibras de madeira, poliestireno/fibras de madeira ${ }^{17}$, etc.;

4 - Capacidade de ser armazenado durante longos períodos sem perda de propriedades;

5 - Flexibilidade no uso do catalisador, que pode ser empregado em suspensão, ou produzido in situ;

6 - Obtenção de catalisadores de alta estereoespecificidade, de baixo custo e fáceis de serem sintetizados.

Quanto à obtenção de polibutadieno com alto teor de unidades repetitivas insaturadas cis, a utilização de catalisadores à base de titânio descrita neste trabalho, no lugar de catalisadores à base de cobalto, usado comercialmente, oferece as seguintes vantagens ${ }^{18}$ :

1 - Maior teor de unidades repetitivas 1,4 cis ( > 90\%);

2 - Estreita polidispersão: $\mathrm{M}_{\mathrm{w}} / \mathrm{M}_{\mathrm{n}}$ entre 1,8 e 2,5 que permite aplicações mais nobres do polibutadieno produzido;

3 - Utilização de catalisador formado in situ o que dispensa a preparação prévia do catalisador e

4 - Baixo teor de gel.

É importante ressaltar que, com exceção de Teses ${ }^{15,18-23}$, não existe na literatura uma descrição completa e detalhada de procedimentos de síntese, bem como dos cuidados especiais necessários devido à alta sensibilidade destes sistemas catalíticos à umidade e ao oxigênio e ao manuseio dos compostos alquil-alumínio (pirofóricos).

Assim, este trabalho tem como objetivo principal a descrição das dificuldades e métodos para sua solução a cada passo da síntese de um catalisador à base de $\mathrm{TiCl}_{3}$. Efeitos negativos produzidos pela presença de algumas impurezas no catalisador e/ou na polimerização de propileno serão também comentados. Será discutido ainda o efeito da concentração de reagentes no 
sistema catalítico preparados in situ baseado em $\mathrm{TiCl}_{4} / \mathrm{I}_{2} / \mathrm{Al}$ (i$\left.\mathrm{C}_{4} \mathrm{H}_{9}\right)_{3}$ na polimerização de butadieno para produzir um polímero com alto teor de unidades repetitivas insaturadas cis.

Todos os detalhes experimentais apresentados neste trabalho são o resultado de estudos desenvolvidos em três Teses de Mestrado e quatro de Doutorado conduzidas sob a orientação de um dos autores no Instituto de Macromoléculas Professora Eloisa Mano da UFRJ.

\section{2 - PARTE EXPERIMENTAL}

\section{1 - Vidraria}

Toda vidraria deve ser seca em estufa a $110^{\circ} \mathrm{C}$ por pelo menos $12 \mathrm{~h}$ e toda aparelhagem deve ser montada ainda quente sob fluxo de $\mathrm{N}_{2}$ seco. Para uma melhor garantia, é recomendado também o uso alternado de $\mathrm{N}_{2}$ e vácuo (três ciclos no mínimo).

\section{$2.2-\mathrm{TiCl}_{4}$}

$\mathrm{O} \mathrm{TiCl}_{4}$ deve ser destilado sob fluxo baixo de $\mathrm{N}_{2}$ seco em grade de destilação provida de torneiras de Teflon. Todas as juntas utilizadas na aparelhagem devem ser envoltas com fita de teflon já que a graxa de silicone é atacada impedindo ou dificultando a abertura da junta.

$\mathrm{O} \mathrm{TiCl}{ }_{4}$ é altamente corrosivo pois gera grande quantidade de $\mathrm{HCl}$ por hidrólise. Durante a sua destilação, o uso de mangueiras de polietileno no condensador é preferível às de látex.

\section{3 - Alquil-alumínio}

As soluções de alquil-alumínio devem ser preparadas em solvente seco e de preferência em concentração máxima de $2 \mathrm{M}$, já que acima desse limite essas soluções são pirofóricas na presença de ar. Além da utilização de equipamento de proteção (capacete com proteção facial, luvas e avental de couro metalizado), é indicado o uso de uma bandeja contendo $\mathrm{CaCO}_{3}$ para utilização em eventuais vazamentos e um extintor de pó químico ao alcance. No caso de cilindros, onde o alquil-alumínio é armazenado sob pressão (Fig. 1), a pressão de $\mathrm{N}_{2}$ da linha externa deve ser verificada antes do início da preparação da solução de alquil-alumínio. Cloreto de dietil-alumínio (DEAC) costuma formar óxidos com maior facilidade do que trietil-alumínio (TEA) ou tri-isobutil-alumínio (TIBA) no sistema de tubos e válvulas que vão do cilindro até o tubo de retirada do alquil-alumínio puro. É recomendável o desmonte desses tubos a cada uso e antes da abertura do cilindro contendo o alquil-alumínio puro, deve ser feito um teste com $\mathrm{N}_{2}$ para verificação de possíveis vazamentos. No caso da utilização de cilindros despressurizados (Fig. 2), onde não existe o sistema de tubos e válvulas, é imprescindível que se faça um teste prévio com um hidrocarboneto comum (iso-octano, hexano, etc.) na seringa que será usada para retirar o alquil-alumínio puro para verificar se há vazamentos.

\section{4 - Éteres}

Éter di-isoamílico (DIAE) e éter di-n-butílico (DBE) PA, secos com fitas de sódio, destilados sob $\mathrm{N}_{2}$ seco em presença de benzofenona e guardados sobre peneira molecular $3 \AA$ ativada.

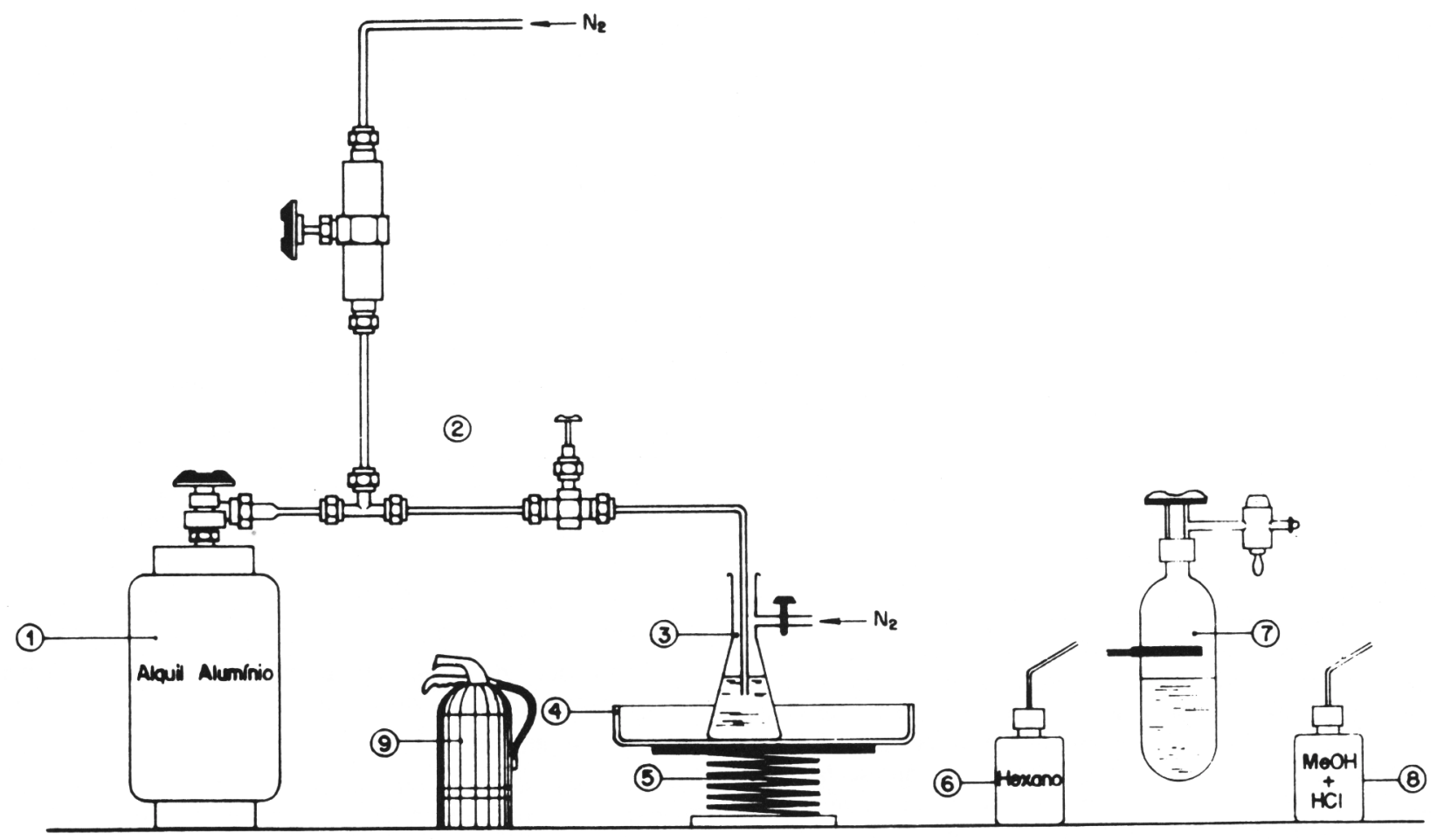

Figura 1. Esquema de preparação da solução de alquil-alumínio contido em cilindro pressurizado

1 - Cilindro metálico contendo alquil-alumínio sob pressão.

2 - Sistema de válvulas e tubos em aço inox.

3 - Erlenmeyer com entrada lateral contendo solvente (hidrocarboneto) para testar se há vazamentos na linha antes da abertura do registro do cilindro metálico e para lavagem de alquil-alumínio da linha no final da operação.

4 - Bandeja contendo $\mathrm{CaCO}_{3}$ utilizada para absorção de alquil-alumínio em caso de acidente.

5 - "Big-jack".

6 - Frasco lavador contendo hexano.

7 - "Schlenk" com solvente seco previamente pesado para preparo da solução de alquil-alumínio.

8 - Frasco lavador com solução aquosa de $\mathrm{HCl} \mathrm{em} \mathrm{MeOH}(5 \% \mathrm{v} / \mathrm{v})$.

9 - Extintor de incêndio de pó químico. 


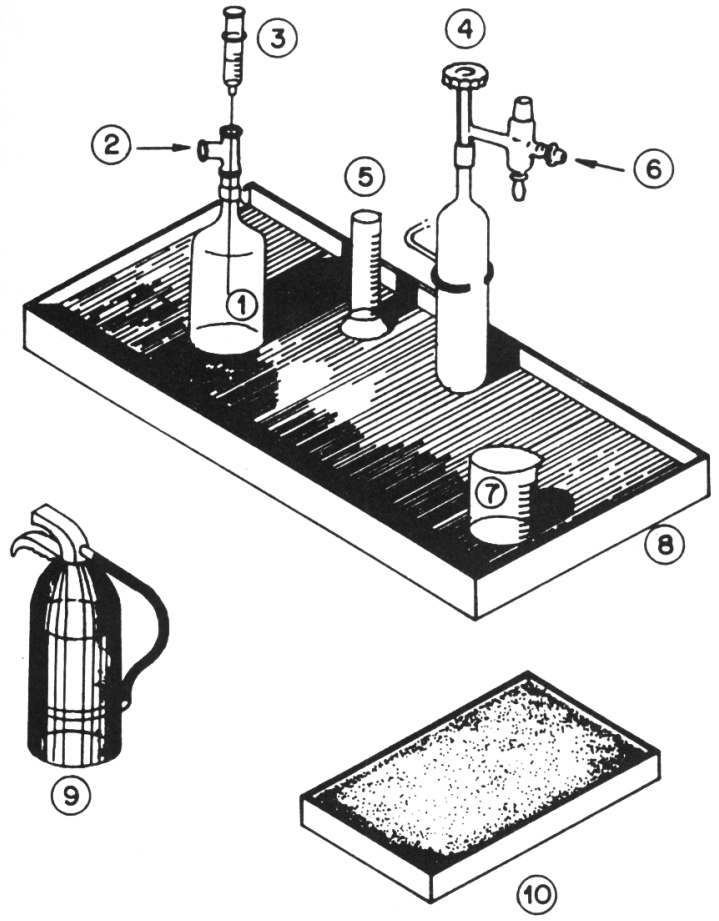

Figura 2. Esquema de preparação da solução de alquil-alumínio contido em cilindro despressurizado

1 - Bala metálica com capacidade para $1 \mathrm{~kg}$ de alquil-alumínio puro. Produto altamente pirofórico.

2 - Entrada de nitrogênio seco para manter atmosfera inerte durante retirada do produto.

3 - Seringa de vidro graduada de $50 \mathrm{ml}$ de capacidade com agulha de aço inox de $25 \mathrm{~cm}$ de comprimento.

4 - "Schlenk" contendo solvente seco para onde será transferido o alquil-alumínio.

5 - Proveta contendo solvente, hexano, utilizada para rinsagem da seringa após a transferência do alquil-alumínio.

6 - Entrada de nitrogênio seco.

7 - Copo de 1 litro, contendo hexano, utilizado para mergulhar as mãos caso respingue alquil-alumínio nas luvas.

8 - Caixa contendo $\mathrm{CaCO}_{3}$, utilizada para absorção de alquil-alumínio em caso de acidente.

9 - Extintor de incêndio de pó químico.

10 - Caixa de areia, para apagar fogo em casos de acidente.

\section{5 - Solventes}

Solventes alifáticos (hexano, heptano, iso-octano), foram borbulhados previamente com $\mathrm{N}_{2}$ seco por $4 \mathrm{~h}$ para a remoção de $\mathrm{O}_{2}$ e secos através de passagem por colunas contendo peneira molecular (13X) ativada.

Tolueno foi refluxado durante $24 \mathrm{~h}$ sobre fitas de sódio, destilado sob $\mathrm{N}_{2}$ seco em presença de benzofenona utilizado logo em seguida.

$\mathrm{O}$ uso de benzofenona como indicador de umidade mostra a eficiência da secagem cujo desenvolvimento da cor azul indica a ausência de água.

\section{6 - Secagem de gases}

A secagem de $\mathrm{N}_{2}$, propileno e butadieno pode ser feita através da passagem do gás por quatro colunas sucessivas, contendo respectivamente $\mathrm{KOH}$, sílica-gel, peneira molecular ativada (3̊̊) e $\mathrm{P}_{2} \mathrm{O}_{5}$ ou, mais simplificadamente, por passagem através de uma coluna maior contendo peneira molecular ativada $(3 \AA)$.

A retirada de $\mathrm{O}_{2}$ dos gases foi feita pela passagem do gás por uma coluna contendo catalisador de cobre (BTS) antes da secagem.

\section{7 - Procedência dos reagentes}

Nitrogênio - grau de pureza $99,995 \%$; teor de umidade e oxigênio máximos igual a 5 ppm (White Martins S.A.)

Butadieno (isento de inibidor) - grau de pureza $>90 \%$, doado pela Petroflex-Coperbo

Propileno - grau de pureza: petroquímico (Petroquímica União); alquil-alumínio (Alkyls do Brasil); éteres - PA (Riedel); $\mathbf{T i C l}_{\mathbf{4}}$ (comercial), iso-octano, hexano, tolueno, BTS (catalisador de cobre da BASF) e peneira molecular $(3 \AA$ e 13X) - doados pela Polibrasil S.A.

\section{8 - Síntese de $\mathrm{TiCl}_{3}$ em três etapas ${ }^{20}$}

\section{Etapa 1 - Redução}

Após a adição da solução de TEA à solução de $\mathrm{TiCl}_{4}$ (a $-65^{\circ} \mathrm{C}$ ou a $0^{\circ} \mathrm{C}$ ), o sistema foi aquecido por 1 hora até $60^{\circ} \mathrm{C}$ e, então, mantido nessa temperatura por mais 1 hora. Foram feitas pelo menos 4 lavagens do $\beta-\mathrm{TiCl}_{3}$ com iso-octano e retiradas alíquotas para adição das diferentes quantidades de base interna e para a determinação do teor de titânio. A concentração das soluções de $\mathrm{TiCl}_{4}$ e TEA em iso-octano foram de respectivamente 0,94 e $0,85 \mathrm{M}$.

\section{Etapa 2 - Tratamento com base interna}

$\mathrm{O} \beta-\mathrm{TiCl}_{3}$ seco foi pesado para cálculo da quantidade de base interna a ser adicionada (mmol base interna/mmol $\mathrm{TiCl}_{3}$ ). Em seguida, foi adicionado um volume mínimo de iso-octano que possibilitasse uma boa agitação da suspensão e finalmente, foi adicionada a base interna. A reação foi conduzida a $35^{\circ} \mathrm{C}$ durante 1 hora sob agitação. Ao final desse período, o $\beta-\mathrm{TiCl}_{3}$ (marrom) foi lavado pelo menos 4 vezes com iso-octano.

\section{Etapa 3 - Reação com $\mathrm{TiCl}_{4}$}

$\mathrm{O}$ sobrenadante do $\beta-\mathrm{TiCl}_{3}$ tratado com base e lavado foi retirado e em seguida o frasco foi pesado para então ser adicionada quantidade mínima de solvente capaz de possibilitar uma boa agitação. Após a pesagem com o solvente, foi adicionado $\mathrm{TiCl}_{4}$ para formação de uma solução a $35 \%$ v/v. A reação foi conduzida a $70^{\circ} \mathrm{C}$ sob agitação durante 2,5 horas ou até que a suspensão se tornasse violeta. $\mathrm{O}$ catalisador violeta $\delta-\mathrm{TiCl}_{3}$ foi então lavado pelo menos 4 vezes com iso-octano e em seguida foi seco para preparação da suspensão de concentração conhecida. Foi retirada uma alíquota dessa suspensão para a determinação do teor de titânio.

\section{9 - Síntese de $\mathrm{TiCl}_{3}$ em etapa única}

$\mathrm{TiCl}_{3}$ pode ser também preparado em uma única etapa, ou melhor, onde todo o preparo do catalisador é realizado em um único reator. Foram realizadas duas séries de síntese, uma com tolueno e outra com iso-octano.

\subsection{1 - Síntese de $\mathrm{TiCl}_{3}$ em tolueno ${ }^{22}$}

Primeiramente foi preparado um banho refrigerante a aproximadamente $-68^{\circ} \mathrm{C}$. Com o auxílio de seringa, $\mathrm{TiCl}_{4}$ destilado foi transferido para um balão previamente pesado contendo $500 \mathrm{ml}$ de tolueno destilado, resultando em solução alaranjada. O balão foi novamente pesado (obtendo-se assim a massa de $\mathrm{TiCl}_{4}$ ) e em seguida deixado no banho refrigerante para atingir a temperatura de equilíbrio.

Tolueno recém destilado, $\mathrm{AlEt}_{3}$ e éter di-n-butílico (DBE) foram transferidos nesta ordem para um funil de adição com o auxílio de seringas. A solução resultante foi adicionada gota a 
gota à solução de $\mathrm{TiCl}_{4}$ em tolueno sob agitação a $-68^{\circ} \mathrm{C}$, obtendo-se um solução marrom escuro. Nessa etapa foram tomados cuidados com o controle da temperatura e velocidade de adição para evitar a redução do $\mathrm{TiCl}_{4}$. Posteriormente, a temperatura foi elevada lentamente $\left(1^{\circ} \mathrm{C} / \mathrm{min}\right)$ de $-68^{\circ} \mathrm{C}$ até $-10^{\circ} \mathrm{C}$ permanecendo nessa temperatura por 3 horas (etapa de redução). Foi obtida no final desta etapa uma solução marrom escuro. A agitação foi interrompida e o banho refrigerante foi substituído por um banho a $65^{\circ} \mathrm{C}$. Após o equilíbrio térmico ser atingido, o fluxo de $\mathrm{N}_{2}$ foi interrompido e o balão foi hermeticamente fechado. $\mathrm{O}$ sistema permaneceu nessa temperatura por 5 horas (etapa de tratamento térmico). Ao término desta etapa foi obtido um sólido de cor marrom com traços de cor violeta. Após ser atingida a temperatura ambiente, o líquido sobrenadante foi decantado e em seguida adicionou-se cerca de $400 \mathrm{ml}$ de iso-octano para a primeira lavagem. A suspensão foi agitada e deixada no banho a $65^{\circ} \mathrm{C}$ por $20 \mathrm{~min}$. Posteriormente, o solvente foi decantado e efetuadas mais 4 lavagens com porções de $400 \mathrm{ml}$ de iso-octano a frio. No decorrer das lavagens a coloração foi mudando de marrom para púrpura $\left(\delta-\mathrm{TiCl}_{3}\right)$. O sólido lavado foi então suspenso em iso-octano em concentração aproximadamente $1 \mathrm{M}$ e assim conservado até o momento de sua utilização.

\subsection{2 - Síntese de $\mathrm{TiCl}_{3}$ em iso-octano ${ }^{21}$}

Foi preparado um banho refrigerante a $-68^{\circ} \mathrm{C} . \mathrm{TiCl}_{4}$ destilado foi transferido com auxílio de seringa para balão previamente tarado contendo quantidade determinada de isooctano. Foi determinada a massa de $\mathrm{TiCl}_{4}$ no balão por diferença de peso. $\mathrm{O}$ balão com a solução de $\mathrm{TiCl}_{4}$ em iso-octano foi deixado no banho para atingir a temperatura de equilíbrio. Foi preparada uma solução de DBE em iso-octano que foi adicionada gota a gota por meio de funil de adição à solução de $\mathrm{TiCl}_{4}$ em iso-octano sob agitação a $-68{ }^{\circ} \mathrm{C}$, obtendo-se um sólido amarelo em suspensão. Solução de DEAC em iso-octano foi adicionada lentamente a essa suspensão por meio do funil de adição. Nessa etapa foram tomados cuidados com o controle da temperatura $\left(-68^{\circ} \mathrm{C}\right)$ e velocidade de adição para evitar a redução do $\mathrm{TiCl}_{4}$. Terminada a adição, a temperatura foi elevada lentamente $\left(1^{\circ} \mathrm{C} / \mathrm{min}\right)$ de $-68^{\circ} \mathrm{C}$ até $0^{\circ} \mathrm{C}$, permanecendo nessa temperatura por 2,5 horas (etapa de redução), ao término dessa etapa foi obtida uma solução que variou de marrom a marrom esverdeada. Em seguida, a agitação foi interrompida e o banho refrigerante foi substituído por um banho a $70^{\circ} \mathrm{C}$. Após ser atingido o equilíbrio térmico, foi interrompido o fluxo de $\mathrm{N}_{2}$ e o balão foi hermeticamente fechado, permanecendo a $70^{\circ} \mathrm{C}$ por 4 horas (etapa de tratamento térmico). Ao final desse tratamento foi obtido um sólido de violeta $\left(\delta-\mathrm{TiCl}_{3}\right)$ que foi em seguida lavado a temperatura ambiente com 4 porções de isooctano. Uma quinta lavagem com iso-octano a $70^{\circ} \mathrm{C}$ foi realizada por 20 minutos. O sólido lavado foi então suspenso em iso-octano em concentração aproximadamente $1 \mathrm{M}$ e assim conservado até o momento de sua utilização.

\subsection{0 - Determinação do teor de titânio em catalisadores baseados em $\mathrm{TiCl}_{3}$}

O teor de titânio dos catalisadores, necessário para o cálculo da concentração da suspensão, foi determinado por método colorimétrico $^{24}$. Este método se baseia no desenvolvimento de cor amarelada resultante da formação do complexo entre $\mathrm{H}_{2} \mathrm{O}_{2}$ e Ti. A intensidade da cor é proporcional a quantidade de Ti presente.

A relação entre a absorbância e a concentração de Ti presente na amostra é dada pela lei de Beer:

$$
\begin{aligned}
& \mathrm{A}=\log \mathrm{Io} / \mathrm{I}_{\mathrm{t}}=\log 1 / \mathrm{T}=\mathrm{acb} \\
& \text { Onde: } \\
& \mathrm{Io} / \mathrm{I}_{\mathrm{t}}=\text { é o inverso da transmitância (a transmitância }
\end{aligned}
$$

representa a fração da potência da radiação incidente que é transmitida pela solução);

$$
\begin{aligned}
& \mathrm{a}=\text { absortividade específica; } \\
& \mathrm{b}=\text { espessura da célula (comprimento do percurso ótico); } \\
& \mathrm{c}=\text { concentração }(\mathrm{g} / \mathrm{l}) .
\end{aligned}
$$

Assim, a absorbância da solução foi medida em espectrofotômetro e a concentração de Ti foi determinada com o auxílio de uma curva padrão de absorbância versus concentração. A determinação do teor de titânio foi feita após a última lavagem do catalisador com iso-octano.

Volume de suspensão equivalente a cerca de $0,25 \mathrm{~g}$ de catalisador foi transferido para frasco com entrada e saída de $\mathrm{N}_{2}$. $\mathrm{O}$ solvente foi evaporado e em seguida o catalisador foi transferido para balão de fundo chato de $250 \mathrm{ml}$ de capacidade contendo $60 \mathrm{ml}$ de solução aquosa de $\mathrm{H}_{2} \mathrm{SO}_{4}$ (1:1). A mistura foi deixada em refluxo por 1 hora e após resfriamento foi filtrada e recolhida em balão volumétrico de $500 \mathrm{ml}$. O volume da solução foi completado com água destilada e deionizada e em seguida homogeneizada. Para dois balões volumétricos de $50 \mathrm{ml}$ contendo $10 \mathrm{ml}$ de solução aquosa de $\mathrm{H}_{2} \mathrm{SO}_{4}$ (1:1), foram transferidas alíquotas de $5 \mathrm{ml}$ da solução da amostra e 5 $\mathrm{ml}$ de solução aquosa de $\mathrm{H}_{2} \mathrm{O}_{2}$ a $10 \%$ em volume. $\mathrm{O}$ volume foi completado com água destilada e deionizada e as absorbâncias das soluções foram medidas $(\lambda=410 \mathrm{~nm})$. Para zerar o espectrofotômetro, foi utilizado um "branco" (com todos os componentes, exceto a solução de titânio).

A curva padrão foi construída a partir de uma solução de titânio em água. Foram lidas as absorbâncias no espectrofotômetro $(\lambda=410 \mathrm{~nm})$ de seis diluições diferentes da solução mãe em balões volumétricos de $50 \mathrm{ml}$ contendo $10 \mathrm{ml}$ de solução 1:1 de $\mathrm{H}_{2} \mathrm{SO}_{4}$ e $5 \mathrm{ml}$ de $\mathrm{H}_{2} \mathrm{O}_{2} \quad 10 \% \mathrm{~V} / \mathrm{V}$.

\subsection{1 - Polimerização de propileno}

As polimerizações foram feitas em balão de 3 bocas de 1 litro de capacidade provido de agitação mecânica e selo apropriado para vedação de gás. As seguintes condições foram empregadas: solvente $=$ iso-octano $(500 \mathrm{ml})$, pressão positiva de propileno $=100 \mathrm{~mm} \mathrm{Hg}$, temperatura $=50^{\circ} \mathrm{C}$, tempo de polimerização $=1$ hora, co-catalisadores = TEA ou DEAC.

A atividade catalítica foi avaliada pela produção de polímero precipitado após 1 hora de polimerização e foi expressa em massa de polipropileno $(\mathrm{g})$ por massa de titânio $(\mathrm{g})$ e por hora (gPP/gTi.h).

A estereoespecificidade catalítica pode ser representada pelo índice de isotaticidade do polímero obtido (I.I. - \% em peso). Este índice é determinado através da extração do polímero bruto em extrator Soxhlet utilizando iso-octano como solvente durante 6 horas.

O I.I. é calculado então pela expressão:

$$
\begin{aligned}
& \text { I.I. }(\%)=\mathrm{Mp}_{2} / \mathrm{Mp}_{1} \times 100 \\
& \text { Onde: } \\
& \text { I.I. = índice de isotaticidade } \\
& \mathrm{Mp}_{1}=\text { massa de polímero bruto } \\
& \mathrm{Mp}_{2}=\text { massa de polímero após a extração }
\end{aligned}
$$

\subsection{2 - Polimerização de butadieno com catalisador preparado "in situ" a base de $\mathrm{TiCl}_{4} / \mathrm{I}_{2} / \mathrm{Al}\left(\mathrm{i}-\mathrm{C}_{4} \mathrm{H}_{9}\right)_{3}$}

A polimerização de butadieno foi realizada em reator de vidro tipo "kettler" com 4 bocas e $500 \mathrm{ml}$ de capacidade equipado com termômetro e um sistema pneumático de agitação mecânica. Após a adição de $250 \mathrm{ml}$ de tolueno tratado, o reator foi imerso em banho a $0^{\circ} \mathrm{C}$. Em seguida, foi feita a transferência para o reator das soluções do catalisador, co-catalisador e iodo, sob agitação do meio reacional a $400 \mathrm{rpm}$, 
com auxílio de seringas graduadas, obedecendo a seguinte ordem de adição: $\mathrm{Al}\left(\mathrm{i}-\mathrm{C}_{4} \mathrm{H}_{9}\right)_{3}$, iodo e $\mathrm{TiCl}_{4}$.

$\mathrm{O}$ reator foi purgado com butadieno por trinta segundos. Em seguida, o reator foi fechado e a reação iniciada. $\mathrm{O}$ monômero foi alimentado continuamente, sendo a sua concentração controlada pela pressão do sistema mantida em $100 \mathrm{~mm}$ $\mathrm{Hg}$ durante o tempo reacional (30 minutos). Após esse período, o sistema catalítico foi desativado pela adição de solução metanólica a $10 \% \mathrm{v} / \mathrm{v}$ de $\mathrm{HCl}$ concentrado e adicionada solução de antioxidante (BHT - 2,6 - di-tert-butil-hidroxitolueno). A mistura mantida sob $\mathrm{N}_{2}$ e agitação, foi então lavada com uma solução de $\mathrm{H}_{2} \mathrm{O}$ (destilada e deionizada) e etanol na proporção de $1 / 1,5$. Finalmente, a fase aquosa (camada inferior) foi separada do polímero por sucção a vácuo.

\section{3 - DISCUSSÃO}

Como já foi mencionado anteriormente, este trabalho tem como objetivo a descrição clara das dificuldades encontradas nos métodos normalmente empregados na síntese de catalisadores Ziegler-Natta baseados em compostos de titânio. Para isso, serão apresentados os problemas e suas soluções encontrados durante o trabalho experimental de Teses desenvolvidas em nosso grupo de pesquisa.

Mesmo em aparelhagens idênticas, a reprodutibilidade de catalisadores depende ainda de fatores, tais como quantidade de catalisador preparado, agitação e modo de adição. À medida que a solução de alquil-alumínio (redutor) é adicionada à solução de $\mathrm{TiCl}_{4}$, a formação de $\mathrm{TiCl}_{3}$ sólido (síntese em três etapas) já pode ser considerada uma variável do sistema. A morfologia do $\mathrm{TiCl}_{3}$ em formação depende do modo como a gota do alquil-alumínio atinge a solução de $\mathrm{TiCl}_{4}$. Adições muito rápidas tendem a formar $\mathrm{TiCl}_{2}$ que por ser pegajoso fica aderido às partículas de $\mathrm{TiCl}_{3}$ modificando a sua morfologia e a atividade catalítica. Adições mais lentas de alquil-alumínio asseguram condições de redução mais brandas. As concentrações das soluções de alquil-alumínio e $\mathrm{TiCl}_{4}$, assim como o tipo de alquilalumínio empregado, também afetam o catalisador, já que são fatores que interferem na velocidade de redução do $\mathrm{TiCl}_{4}$.

Um outro problema também ligado a reprodutibilidade na síntese de catalisadores é a facilidade do tolueno em absorver água. No início de nossos experimentos, o tolueno era destilado na presença de fitas de sódio, sob atmosfera de $\mathrm{N}_{2}$ seco, tendo sido primeiramente refluxado por 4 horas, e, então, recolhido sobre peneira molecular ativada e armazenado para uso posterior. Com essa metodologia, não se conseguia reprodutibilidade na síntese dos catalisadores. Esse problema foi solucionado usando-se somente tolueno recém destilado (Tabela 1$)^{22}$.

Tabela 1. Reprodutibilidade da síntese do catalisador.

\begin{tabular}{ccc}
\hline № da síntese & $\begin{array}{c}\text { Atividade } \\
\text { catalítica } \\
\text { (gPP/gTi.h) }\end{array}$ & $\begin{array}{c}\text { Índice }^{\text {de }} \\
\text { isotaticidade } \\
(\%)\end{array}$ \\
\hline 1 & 465 & 96,0 \\
2 & 473 & 96,5 \\
3 & 460 & 95,0 \\
\hline
\end{tabular}

$\overline{a)}$ Determinado através da extração com iso-octano em Soxhlet durante 6 horas; DBE - éter di-n-butílico; gPP - massa de polipropileno (g); gTi - massa de titânio (g); h - tempo (h). Condições de síntese:

$\mathrm{DBE} / \mathrm{TiCl}_{4}=0,8 ; \mathrm{TiCl}_{4} / \mathrm{AlEt}_{3}=5 ;$ Tempo de redução $=3$ horas Temperatura de redução $=-10^{\circ} \mathrm{C}$; Tempo de tratamento térmico $=5$ horas; Temperatura de tratamento térmico $=65^{\circ} \mathrm{C}$.

Por outro lado, solventes como hexano e iso-octano não necessitam de cuidados tão extremos como no caso do tolueno, pois são menos hidrofílicos ${ }^{20}$.
Os catalisadores sintetizados em três etapas foram preparados em um laboratório (LAB 1 - Projeto de pesquisa em colaboração Polibrasil S.A.) onde a peneira molecular de $3 \AA$ que fazia parte do recheio das colunas de secagem tinha sido ativada a $110^{\circ} \mathrm{C}$ em estufa durante 12 horas e transferida ainda quente para a coluna sob fluxo de nitrogênio.

Os catalisadores preparados em etapa única foram sintetizados no LAB 2 (laboratório de pesquisa de catalisadores ZieglerNatta) onde as colunas contendo peneira molecular tinham sido ativadas a $300^{\circ} \mathrm{C}$ durante 6 horas sob fluxo de nitrogênio.

Embora os catalisadores preparados no LAB 1 não tenham sido desativados completamente, várias evidências mostraram a presença de água no sistema:

$1-\mathrm{TiCl}_{3}$ anidro forma uma solução violeta em meio aquoso. Foi observado que a solução aquosa de $\mathrm{TiCl}_{3}$, empregada na determinação do teor de titânio, preparada a partir dos catalisadores sintetizados no LAB 1 tornava-se amarelada, enquanto que as soluções preparadas no LAB 2 eram violeta.

2 - $\mathrm{TiCl}_{4}$ destilado mantido no LAB 1 tornava-se amarelado após alguns dias, enquanto que no $\mathrm{LAB} 2 \mathrm{o} \mathrm{TiCl}_{4}$ permanecia incolor. Provavelmente, as seguintes reações ${ }^{25}$ ocorriam no LAB 1:

$$
\begin{array}{ll}
\mathrm{TiCl}_{4} & \mathrm{TiOCl}_{3}+\mathrm{HCl} \\
& \text { (Sólido amarelo) }
\end{array}
$$

$$
\begin{array}{ll}
\mathrm{TiCl}_{4}+2 \mathrm{H}_{2} \mathrm{O} & \mathrm{TiO}_{2}+4 \mathrm{HCl} \\
2 \mathrm{Hcl}+\mathrm{TiCl}_{4} & \begin{array}{l}
\mathrm{H}_{2} \mathrm{TiCl}_{6} \\
(\text { amarelo })
\end{array}
\end{array}
$$

3 - Difratogramas de raios-X de alguns catalisadores preparados no LAB 1 mostraram a presenca de $\mathrm{TiCl}_{3} \cdot 6 \mathrm{H}_{2} \mathrm{O}$ como impureza presente no $\mathrm{TiCl}_{3}$ obtido ${ }^{20}$.

4 - Quando uma coluna contendo $\mathrm{P}_{2} \mathrm{O}_{5}$ foi utilizada para secar o propileno do LAB 1, a atividade do catalisador aumentou consideravelmente.

O sistema catalítico utilizado para a síntese de polibutadieno com alto teor de unidades repetitivas insaturadas cis é extremamente sensível a impurezas, tais como água e oxigênio. A tabela 2 reúne inúmeras reações feitas rigorosamente nas mesmas condições sem se conseguir, entretanto, reproduzí-las em termos de atividade catalítica.

Tabela 2. Sensibilidade do sistema $\mathrm{TiCl}_{4}+\mathrm{I}_{2}+\mathrm{Al}(\mathrm{i}-\mathrm{Bu})_{3}$ em relação à presença de impurezas.

\begin{tabular}{cc}
\hline Número da reação & $\begin{array}{c}\text { Produtividade } \\
(\mathrm{gPB} / \mathrm{mmol} \text { Ti })\end{array}$ \\
\hline 1 & 75 \\
2 & traços \\
3 & 120 \\
4 & 92 \\
5 & 33 \\
\hline Condições reacionais: solvente $=$ tolueno; pressão de butadieno \\
$=100 \mathrm{~mm} \mathrm{Hg} ;$ razão molar $\mathrm{Al} / \mathrm{Ti}=8 ;$ tempo $=30$ min; razão \\
molar $\mathrm{I}_{2} / \mathrm{Ti}=1,5 ;$ temperatura $=20^{\circ} \mathrm{C} ;$ velocidade de agitação \\
$=400 \mathrm{rpm} ;\left[\mathrm{TiCl}_{4}\right]=1$ mmol $/ 1$
\end{tabular}

Embora nenhuma condição de reação tenha sido alterada, pois o objetivo era reproduzir as reações, a atividade catalítica do sistema apresentou variações bastante significativas, provavelmente devido à ocorrência de desativação dos sítios ativos provocadas pela presença de impurezas no meio reacional, provavelmente água e oxigênio. Uma série de cuidados especiais foram então tomados para se conseguir uma boa reprodutibilidade das reações (Tabela 3 ): 
- vidraria extremamente limpa e seca durante um período relativamente longo;

- utilização de baixas concentrações das soluções do sistema catalítico;

- preparo diário das soluções de tetracloreto de titânio;

- destilação quinzenal de tetracloreto de titânio;

- preparo quinzenal das soluções de TIBA e iodo;

- utilização do solvente destilado até no máximo 24 horas após a destilação;

- eliminação de ar do solvente imediatamente antes da reação;

- manutenção do sistema de destilação do solvente $24 \mathrm{~h} /$ dia com fluxo de nitrogênio super seco;

- purga exaustiva de todo o sistema reacional com monômero imediatamente antes do início da reação.

Tabela 3. Reprodutibilidade na polimerização de butadieno com o sistema catalítico $\mathrm{TiCl}_{4}+\mathrm{I}_{2}+\mathrm{Al}(\mathrm{i}-\mathrm{Bu})_{3}$.

\begin{tabular}{cc}
\hline Número da reação & $\begin{array}{c}\text { Produtividade } \\
(\mathrm{gPB} / \mathrm{mmol} \text {.Ti })\end{array}$ \\
\hline 6 & 52 \\
7 & 54 \\
8 & 50 \\
9 & 52 \\
10 & 50 \\
\hline
\end{tabular}

Condições reacionais: as mesmas indicadas na Tabela 2.

O preparo da solução de TIBA (ou de outro alquil-alumínio) apesar de relativamente simples é extremamente perigoso, e após se analisar um determinado número de reações, optouse pela renovação quinzenal dessa solução. A solução de TIBA é preparada em frascos tipo "Schlenk" de pequeno diâmetro, visando diminuir a área exposta, reduzindo assim a hidrólise do alquil-alumínio. O composto alquil-alumínio é introduzido após o solvente, e a concentração é calculada por diferença de peso. Esta solução deve ser homogeneizada logo após o seu preparo, pois o alquil-alumínio tende a separar fase no solvente.

A solução de $\mathrm{TiCl}_{4}$ em tolueno deve ser bem homogeneizada antes de sua utilização, uma vez que a diferença de densidade entre o soluto $\left(1,726 \mathrm{~g} / \mathrm{cm}^{3}\right.$ a $\left.20^{\circ} \mathrm{C}\right)$ e o solvente $\left(0,866 \mathrm{~g} / \mathrm{cm}^{3}\right.$ a $20^{\circ} \mathrm{C}$ ) é grande.

O butadieno utilizado era recebido já isento de inibidor. Sendo um gás extremamente reativo, optou-se por recebê-lo em cilindros de volume pequeno (5 litros), para não concentrá-lo em peróxidos, que se formariam durante períodos longos de estocagem a temperatura ambiente e que poderiam provocar explosão.

\section{CONCLUSÕES}

Embora catalisadores à base de $\mathrm{TiCl}_{3}$ não sejam de última geração, ainda são utilizados em muitas plantas industriais de polipropileno. No Brasil há pelo menos duas plantas, uma em São Paulo e outra no Polo Petroquímico de Camaçari que produzem polipropileno com catalisador de geração anterior ao relatado neste trabalho.

Todos os cuidados necessários para a manipulação dos catalisadores Ziegler-Natta à base de $\mathrm{TiCl}_{3}$ são os mesmos de gerações mais avançadas ou mesmo para os metalocênicos. Assim, um bom treinamento com estes sistemas é de grande utilidade para qualquer catalisador tipo Ziegler-Natta.

Pelo que foi relatado neste trabalho é possível verificar que as condições de reação (concentração dos reagentes, tipo de solvente, ordem de adição dos reagentes, temperatura de reação e de tratamento térmico, tempo de tratamento térmico e secagem, temperatura de secagem, etc.) têm grande influência no desempenho do catalisador obtido. Finalizando, nenhum resultado confiável pode ser obtido se, cuidados especiais de manipulação e técnica não forem tomados.

\section{AGRADECIMENTOS}

Os autores agradecem ao CNPq, CAPES, CEPG/UFRJ, Petroflex e em especial à Polibrasil S.A. pelo apoio financeiro que vem dando a linha de pesquisa sobre catalisadores ZieglerNatta do IMA/UFRJ.

\section{REFERÊNCIAS}

1. Hermans, J. (Solvay \& Cie) - Patente Americana 4.210.738, 1980 .

2. Huff, T. (Exxon Research and Engineering Co.) - Patente européia 0116227, 1984.

3. Abe, T.; Geko, N.; Nishihara, Y.; Matsuda, Y.; - Patente brasileira 7802131,1978.

4. Goodyear Tyre \& Rubber Co. - Patente inglesa 1.069.922, 1967.

5. Phillips Petroleum Co. - Patente inglesa 931.440, 1963.

6. Coutinho, F. M. B.; Costa, M. A. S.; Santa Maria, L. C.; Polym. Bull., 1992, 28, 55.

7. Coutinho, F. M. B.; Costa, M. A. S.; Santos, A. L. S.; Costa, T. H. S.; Santa Maria, L. C.; Pereira, R. A.; Fresenius J. Anal. Chem. 1992, 344, 514.

8. Coutinho, F. M. B.; Santa Maria, L. C.; Eur. Polym. J. 1991, 27, 987.

9. Coutinho, F. M. B.; Santa Maria, L. C.; Polym. Bull. 1991, 26, 535.

10. Coutinho, F. M. B.; Santa Maria, L. C.; Costa, T. H. S.; Pereira, R.; Eur. Polym. J. 1992, 28, 695.

11. Coutinho, F. M. B.; Santa Maria, L. C.; Polym. Bull. 1992, 29, 193.

12. Costa, M. A. S.; Coutinho, F. M. B.; Polímeros: Ciência e Tecnologia 1992, Out/Dez, 38.

13. Boor Jr., J.; Ziegler-Natta Catalysts and Polymerizations, Academic Press; New York, 1979.

14. Muñoz-Escalona, A.; Hernández, J. G.; Advances in Polyolefins (Seymor, R. B.; Cheng, T.; Eds.), Plenum Press; New York 1986, p. 179.

15. Forte, M. M. C.; Tese de Doutorado, IMA-UFRJ, 1995.

16. Forte, M. M. C.; Miranda, M. S. L.; Química e Derivados 1995, Mar, 28.

17. T. H. S. Costa; M. A. S. Costa; F. M. B. Coutinho; L. C. Santa Maria; Proc. $2^{\text {nd }}$ Ibero-American Polymer Symposium, $4^{\text {th }}$ Latin-American Polymer Symposium, $6^{\text {th }}$ Interna-tional Macromolecular Colloquium, ABPol, 1994, p. 624.

18. Pires, N. M. T.;Tese de Mestrado, IMA-UFRJ, 1990.

19. Magalhães, D. S. S. N. T.; Tese de Mestrado, IMA-UFRJ, 1990.

20. Costa, T. H. S.; Tese de Mestrado, IMA-UFRJ, 1991.

21. Santa Maria, L. C.; Tese de Doutorado, IMA-UFRJ, 1992.

22. Costa, M. A. S.; Tese de Doutorado, IMA-UFRJ, 1995.

23. Marques, M. F. V.; Tese de Doutorado, IMA-UFRJ, 1993.

24. Vogel, A.I. - Quantitative Inorganic Analysis, Longman Guen and Co.; New York, 1951.

25. Neville, G. H. J. - Encyclopedia of Chemical Technology, Interscience Publishers; New York 1969, 20, 380. 